\title{
Visual Media as a Factor in the Mental Health of Today's Youth
}

\author{
Hanna Abanina *[0000-0003-4064-724X], Syed Baqri [0000-0002-6868-0511] \\ «KROK» University, Kyiv, Ukraine \\ *hannaav@krok.edu.ua
}

\begin{abstract}
The peculiarities of the influence of visual media on the mental health of the individual are considered, in particular the relationship between the active use of retouched body images in the media and the increasing prevalence of eating disorders is noted. The effects of photo manipulations on the formation of body image in modern Ukrainian youth are analyzed. It has been established that the effect of the impact of visual media can form a negative body image of one's self, which further causes mental health disorders like low self-esteem and rejection of their appearance to serious mental illness. The ways of solving this problem are outlined specifically in the world of legal framework, which regulates the issues of body image formation in the modern visual media space. Among the most effective ways to prevent the negative impact of visual media on the psyche of the individual identified the education about the visual media culture of modern youth.
\end{abstract}

Keywords: visual social media, visual media communication, photo manipulation, body image, mental health.

\section{INTRODUCTION}

Modern multimedia communication technologies are characterized by a shift of emphasis from verbal means of communication to visual ones. Perceptual processes of modern man are tuned to the visual perception of information. The perception of verbal and textual information is leveled and devalued [1]. We can say that today "the picture wins the word." In particular, it is well known that about $70 \%$ of advertising is noticed primarily due to stylish, beautiful, elegant images of goods. Marketers, advertisers, manufacturers understand the importance of the visual image and accordingly use advanced photo editing software, use various manipulations [2; 3] to improve the image, which eventually become the joint work of makeup artists, hairdressers, photographers and retouching experts, far from the real image.

As a result of popularization by the mass media of "false" and "retouched" standards of external attractiveness, the subjective perception of an individual's physical image has been transformed, which probably causes internal conflicts, low self-esteem, distortion of self-perception to different kinds of psyche [4].
The urgency of this topic is evidenced by the appearance of a number of scientific and journalistic works on the ethical use of digital editing in photojournalism. For example, in the United States, the National Press Photographers Association of (NPPA) has established a Code of Ethics that supports the accuracy of published images, recommending that photographers not manipulate images that may mislead viewers or misrepresent objects.

The aim of our study was to identify and describe the effects of visual media on the formation of body image and mental health of modern Ukrainian youth.

\section{THEORETICAL METHODOLOGICAL BASES OF RESEARCH}

Marketing campaigns require only high-quality images with perfect contrast, color and exposure, so advertising companies prefer to outsource them to companies such as Image Processing Services India, which use stunning images with ideal editing tools in the required resolution and format. Photo editing is not just a part of advertising in the fashion and beauty industry. It is also a huge part of the consumer industry advertising. 
Photo manipulation covers a range of methods used in various industries. It is often called "retouching" or "airbrushing". Photo manipulation has become possible with the advent of new multimedia technologies. The prePhotoshop era can be seen as a time when photographs were images of indisputable truth at a given point in time. "Beauty in the eyes of the beholder" however, beauty in modern photographic images is, so to speak, an "enhanced version of reality", a certain simulacrum, in contrast to the raw, realistic image

It is well known fact that modern social media plays a significant role in the formation of the standard of "perfect beauty" [5]. In order to improve the real image, many photo and video correction applications are created. The final results of image processing can be extremely different from the original source in appearance, color of hair, body shape, skin tone, etc. [6].

Numerous studies have shown that the effect of such media influence can be the formation of a negative image of your body, which further leads to the development of serious mental illness, including dysmorphophobia - a mental disorder characterized by the obsession that a certain part of your body or its external appearance are very ugly and require exceptional measures to hide these shortcomings [7].

Body image is a person's perception of the aesthetics or sexual attractiveness of his own body, which also includes memories, experiences, assumptions, comparison of one's own appearance with the standards set by society. Despite the fact that society has always attached great importance to the beauty of the human body, a person's perception of his own body may not meet the norms of society [8]. As a result, a person's mind forms a negative attitude towards their own body image and underestimates their appearance, because in the process of media communication [9] through visual messages, products of the TV and film industry, social networks, advertising, magazines and others, there is a comparison of oneself with the participants of such communications with a perfectly retouched appearance. As a result of the impact of such "fake" information, there is a threat of the spread of psychological disorders, chronic stress, feelings of inferiority and non-compliance with the standards set by the media society. The most vulnerable group of media influence is young people who try to form their body image, resembling the visually perceived ideals of modern media space [10].

Numerous studies indicate a link between the active use of retouched body images in the media and the increasing prevalence of eating disorders [11]. In particular, in the United Kingdom, a study conducted by Dove in 2000s on self-perception of their appearance, which showed that only $2 \%$ of women considered themselves beautiful. The survey was conducted through telephone (the total number of respondents were 3,200 women aged 18 to 64 in ten countries). Interviews were conducted in countries such as the United States, Canada, United Kingdom, Italy, France, Portugal, Netherlands,
Brazil, Argentina, and Japan. In each country, 300 interviews were conducted, in the US - 500. Drawing the appropriate conclusions, the brand Dove has chosen a development strategy based on the imitation of "beauty for all", respectively, began to use in all its images only real women of all ages body size, nationality, hair color, etc. [8].

The urgency of the above problems is also evident by the development of the global legal framework, which regulates the issue of body image. This area of law, according to Dr. Marilyn Bromberg of the University of Western Australia Law School and Cindy Halliwell, a law student at Dickin University, "includes bills, laws, and government action to help improve the image of the general public, including young people" [6]. Among the main objectives of such legislation is to prevent serious eating disorders. The Israeli government also provide state support for this issue. The country has a law on body image (in force since 2013), which regulates the requirements for compliance of parameters of photo and video models with certain standards. This regulates the minimum body mass index of the model involved in the work, as well as the presence of a mandatory label, if the appearance of the image was made with any corrections in order to visually reduce the actual dimensions of the body [12]. The French government passed a similar law in 2015, which came into force in 2017. This law requires models to provide their employers with "a medical certificate valid for up to two years, confirming their general physical well-being and the fact that they are not medically thin" [13]. In Ukraine, unfortunately, the issue has not yet received state support, so its research will provide information on the impact of visual media on the self-perception of Ukrainians and will provide an opportunity to compare the results of such studies with those conducted by scientists in other countries.

\section{ANALYSIS OF RESEARCH RESULTS}

We conducted a study to establish the peculiarities of the relationship between manipulated (retouched) photos presented on social networks and the body image of Ukrainian youth. The main objectives of our study were to consider various global policy initiatives aimed at regulating digital retouching to reduce harm to consumer health, as well as to identify the effects of social media [14], advertising, photo manipulation, selfies on selfperception and self-esteem of modern youth. An author's questionnaire was developed to solve the set tasks.

The sample consisted of 90 people aged between 15 to 28 years, including 25 men and 65 women. In our opinion the most important are the results. To the question in the questionnaire "In your opinion, are the images of models in advertising, social media or instagram models real (without the use of photo editing tools?" $43 \%$ of respondents said they believe such photos are real, without any effects or editing in Photoshop. At the same time, $34 \%$ of respondents consider modern beauty standards to be realistic, i.e they refer to lip augmentation, 
use of breast implants, removal of ribs as normal phenomena in the field of beauty.

$44 \%$ of participants said they do not post their photos on their social media such as Facebook or Instagram without editing, which includes improving skin color, texture, increasing or decreasing body size, filters, and more. At the same time, $46 \%$ of young people believe that they look the same in real life and in photos, $25 \%$ are dissatisfied with their natural photos, $78 \%$ are satisfied with their photos only after editing them.

The findings are based on psychological research from Flinders University, which found that the longer women edited and posted selfies, the worse their mood became and the more dissatisfied they were with their appearance. The women in this study spent about 4 minutes editing up to five selfies to smooth and change skin tone, remove dark circles under the eyes, shape the face, and eliminate other imperfections. Flinders University researcher Marika Tiggemann emphasizes that investing time and effort in taking, selecting and editing selfies is a harmful practice that has a detrimental effect on women who are motivated to present the best possible version of themselves [15].

For question "Do you feel discomfort self body-image when you look at the photos of models?" $37 \%$ of respondents answered yes, and to the question "Do you think that you need to improve your body to meet the standards of modern beauty?" we received $54 \%$ positive answers. We consider this figure to be quite high and it indicates a high level of dissatisfaction with their appearance among young people, primarily due to the influence of modern visual media. It is worth noting that today's young people do not claim to improve their physical appearance, but instead want some changes in the perception of their body, as they have a strong sense of non-compliance with the imposed standards of beauty. Modern media is guaranteed to "draw" its consumers into virtual edited images: they are increasingly comparing themselves not with the immediate environment, but with strangers from social networks, celebrities and their manipulated photos, which we can perceive about 5,000 a week.

Answers to the question "Do your friends usually use Photoshop edits, effects, filters on their photos?" in relation to the answers to the question "Do you post your photos only after editing on social networks?" have an interesting indirect relationship: $95 \%$ of young people believe that their friends use photo editing, while $44 \%$ say they cannot share their photos without editing. Based on this, we can say that people are usually dissatisfied with their natural appearance, and photo editing is the only decision they make to compete with modern standards of beauty. Our results are to some extent correlated with the results of the TruePic 2017 survey [16].

It was allegedly found that $93 \%$ of the 2,133 adults surveyed assumed that other people posted mostly edited photos on social media websites. Of this group, 58\% said they do not trust dating sites primarily because of edited photos, $48 \%$ said they do not trust fitness or weight loss photos, and $46 \%$ doubted the reality of photos posted on social networks. On the other hand, $64 \%$ of respondents admitted that they edit their photos online. Here arises the question of double standards: people consider it normal to edit their images, at the same time they do not trust other people's edited images.

We also found that $69 \%$ of young people think that their friends want to look like models, while $60 \%$ of them think that their acquaintances want to meet the general idea of modern beauty standards created by photos of models, in other words try to compete with fake modern standards of beauty, a certain ideals that cannot be achieved in real life. To some extent, trying to have a beautiful appearance is good, but provided that a person makes some effort to do so and thus develop, both physically and psychologically, lead a healthy lifestyle. The problem arises when young people make neither physical nor moral efforts to improve their appearance, while wanting to meet the foamy ideals of beauty. As a result, it can lead to a deterioration in mental health, including various kinds of interpersonal conflicts, psycho-emotional disorders, problems with self-esteem, and so on.

To some extent the above research results can be explained by the effects of social pressure, social desirability, as well as the phenomenon of "remote bias", which was described by us in previous works [17].

"Remote bias" is that some users on social networks follow the lives of others more and talk less about themselves. While they are watching others, their own lives pass by, that is in fact in social networks there is a tendency to live "the lives of others." Given that people try to present themselves on the web pages at their best, those who watch the lives of others more have the illusion that others are happier and more beautiful. Hence the feeling of dissatisfaction with their own lives, low selfesteem, depressed mood [18].

An indirect indicator of the influence of visual media on the perception of young people of their appearance can be considered that $7 \%$ of the youth audience we interviewed want to have plastic surgery. The use of plastic surgery is becoming common not only in the beauty industry, show business, but also among other segments of the population, including young age. According to the American Society of Plastic Surgeons for the period 2000-2018, the number of minimally invasive procedures has tripled [19].

In particular, in 2018, almost 18 million surgical or minimally invasive procedures were performed against 15 million in 2013. In 2017, 55\% of cosmetic surgeons reported interacting with clients whose goal was to improve their appearance for selfies. British plastic surgeon Tijon Esho in this context proposed the concept of "Snapchat Dysmorphia" [20]. which went beyond the professional circle of plastic surgeons and began to be actively used in the psychological field. The ability to use photo editing programs contributes to users losing touch 
with reality because they expect to look perfect and filtered in real life. Moreover, as noted by psychology professor Rene Engeln, "the realization that the image has been edited does not prevent our brain from perceiving it as real" [21].

At the end of our study, we asked the question "Do you support the idea of adopting a rule necessary place a warning sign in advertising that the used photo of the model was edited and and in real life the model may look different?". 78\% of respondents supported this idea of a warning label "Edited Photo" in the advertisement. In this context, it should be noted that countries such as Israel, the United Kingdom, France and Australia have already adopted the Body Image Act, which requires that any advertisement that uses edited photographs be notified. A fine of 32,000 euros was imposed for non-compliance with this law. The idea of the law is primarily to inform media consumers about the difference between real and edited images, which is likely to help prevent a number of psychological disorders such as low self-esteem, food distribution, psycho-emotional sphere, and so on.

We consider one of the most effective approaches of preventing the negative impact of visual media on the mental health of modern youth is by education in psychology, aimed at forming critical thinking and creative perception of visual media products. According to N.I. Cherepovska, one of the leading domestic researchers of the problem of modern visual media culture, "media education, and in the media psychological format, is able to form such personal qualities that will help a young person to constructively build their lives in modern media reality. That is, the main purpose of media education is the formation of youth media culture and, including visual media culture" [22].

Thus N.I. Cherepovska proposes to consider such criteria of the developed media culture of the individual, and visual media culture in particular, as: 1) a conscious attitude to the perception of media products and information in general; 2) critical thinking; 3) creative media perception and vision. In the context of the problem outlined in our study, important areas of formation of visual media culture may be: the development of the ability to filter visual information, conscious restriction in the consumption of media and visual products, awareness of their media needs and responsibility for media content, development of ability to analyze visual ability to weigh the benefits or harms of interaction with the media image, autonomous attitude to media and visual information. In general - understanding the place of man in interaction with visual media, a global vision of the world of media reality with its patterns and trends [22, 23].

\section{CONCLUSION}

The use of photo manipulation in visual media creates unrealistic standards of beauty, which are almost impossible to achieve in real life. However, with uncritical perceptions of such edited visual information, young people may seek to meet imposed standards, which is likely to cause a variety of mental health problems. The results of the study indicate the relevance of this problem of the influence of social standards of external attractiveness, created by visual media, on the subjective perception of his body image by a young person.

It has been found that the effect of visual media can be the formation of a negative image of your body, which further causes mental health disorders, from low selfesteem to serious mental illness such as dysmorphophobia.

The solution of the outlined problem should be complex, include different levels: social, legislative, socio-psychological, clinical. One of the most effective ways to prevent the negative impact of visual media on the mental health of young people is identified as a media educational psychological approach aimed at forming critical thinking and creative perception of visual media information.

\section{REFERENCES}

[1] Rudchenko, A.S. (2017), "Visualization as a trend in modern convergent media", Materialy naukovoi konferentsii. DNU. vol. 1, pp. 68-69, available at: https://jpvs.donnu.edu.ua/article/view/3688.

[2] Abhishek Maity (2016), "Improvised Salient Object Detection and Manipulation", International Journal of Image, Graphics and Signal Processing, vol. 8, no. 2, pp. 53-60. DOI: 10.5815/ijigsp.2016.02.07

[3] Hussein AlNabulsi, Izzat Alsmadi and Mohammad Al-Jarrah (2014), "Textual Manipulation for SQL Injection Attacks", IJCNIS, vol. 6, no. 1, pp. 26-33. DOI: $10.5815 / \mathrm{ijcnis.2014.01.04}$

[4] Sharma, G.T. (2018), "An Efficient Adaptive based Median Technique to De-noise Colour and Greyscale Images", available at: http://www.mecspress.org/ijmecs/ijmecs-v10-n2/IJMECS-V10-N26.pdf.

[5] Imrana, A. Faiyazb, M. Akhtar, F. (2018), “An Enhanced Approach for Quantitative Prediction of Personality in Facebook Posts", available at: http://www.mecs-press.org/ijeme/ijeme-v8n2/IJEME-V8-N2-2.pdf.

[6] How Technology and Social Media Influences Body Image (2020), available at: https://www.eatingdisorderhope.com/blog/bodyimage-technology

[7] Davidenko, K. (2020), "Dysmorphophobia: clinical picture and methods of treatment", Ukrainskyi medychnyi chasopys, available at: https://www.umj.com.ua/article/159691/dismorfof obiyaklinichna-kartina-ta-metodi-likuvannya. 
[8] Matiiko, T. (2020), "They wanted to sell soap, but changed the world management of beauty", available

at: http://practicum.space/khotily_prodaty_mylo_a_z minyly_uiavlennia_pro_krasu.

[9] Mortaza Nikzad, Ali Bohlooli and Kamal Jamshidi (2015), "Video Quality Analysis of Distributed Video Coding in Wireless Multimedia Sensor Networks", International Journal of Information Technology and Computer Science, vol. 7, no. 1, pp. 12-20. DOI: 10.5815/ijitcs.2015.01.02

[10] Aryna, H.A. and Martinov, S.E. (2009), "Capture the mass information as a factor of disagreement preoccupation with one's own appearance in adolescence", Kulturno-ystorycheskaia psykholohyia. Tom 5, № 4, pp. 105-114.

[11] Using Technology to Support Eating Disorder Recovery (2020), available at: https://www.eatingdisorderhope.com/blog/usingtechnology-tosupport-eating-disorder-recovery.

[12] Pieche, D. (2017), "Countries around the world have made laws against photoshopping bodies, but is it really helping the body positivity movement?", University of Southern California Annenberg Media, available at: http://www.uscannenbergmedia.com/2017/11/30/c ountriesaround-the-world-are-actively-makinglaws-banning-photoshopand-hiring-models-whoare-too-thin-but-is-it-helping-the-bodypositivitymovement/.

[13] Friedman, V. (2017), "A New Age in French Modeling", The New York Times.

[14] Monika Mangla, Smita Ambarkar and Rakhi Akhare (2020), "A study to Analyze impact of social media on society: WhatsApp in particular", International Journal of Education and Management Engineering, vol. 10, no. 1, pp. 1-10. DOI: 10.5815/ijeme.2020.01.01

[15] Tania Bawden (2020), Flinders University, available at: https://blogs.flinders.edu.au/fit/2020/05/01/editingselfies-is-counter-productive-study/.

[16] TruePic Survery (2017), available at: https://www.globenewswire.com/newsrelease/2017/05/18/1312618/0/en/The-FilterEffect-People-Distrust-Websites-Because-ofManipulated-Photos.html.

[17] Myronenko, H.V. (2015), Chas virtualnoho zhyttia [Virtual life time], NAPN Ukrainy, ISPP, Kyiv, $134 \mathrm{p}$.

available https://library.krok.edu.ua/media/library/category/ monografiji/abanina_0002.pdf.

[18] Manglaa, M. Ambarkarb, S. Akharec, R. (2020), “A study to Analyze impact of social media on society", available at: http://www.mecspress.org/ijeme/ijeme-v10-n1/IJEME-V10-N11.pdf.

[19] Statistics between 2000 - 2018 (2020), available at: https://www.plasticsurgery.org/news/pressreleases/new-statistics-reveal-the-shape-of-plasticsurgery.

[20] Snapchat Dysmorphia (2020), available at: https://www.ncbi.nlm.nih.gov/pmc/articles/PMC59 33578/.

[21] Renee Engeln 2012 (2020), available at https://journals.sagepub.com/doi/10.1177/0361684 312441593 .

[22] Cherepovska, N.I. (2014), VIZUALNA MEDIAKULTURA: rozvytok krytychnoho myslennia i tvorchoho spryimannia [CULTURE OF VISUAL MEDIA: development of critical thinking and creative perception], Kyv, Milenium, 115 p. available

http://mediaosvita.org.ua/book/vizualnamediakultura-rozvytok-kr/.

[23] Akinyemi, B. Adewusi, O. Oyebade, A. (2020), “An Improved Classification Model for Fake News Detection in Social Media", available at: http://www.mecs-press.org/ijitcs/ijitcs-v12n1/IJITCS-V12-N1-5.pdf. 